\title{
Detection of miR-1246, miR-23a and miR-451 in sera of colorectal carcinoma patients: a case-control study in Cairo University hospital
}

\author{
Mona Salah ${ }^{1}$, Iman Shaheen ${ }^{1}$, Pakinam El-Shanawany ${ }^{2}$, Nagwa Eid Saad ${ }^{2}$, \\ Rasha Saad ${ }^{2}$, Mahmoud El Guibaly ${ }^{3}$, Nouran Momen ${ }^{1}$
}

1. Clinical and Chemical Pathology Department, Faculty of Medicine, Cairo University.

2. Family medicine department, Faculty of Medicine, Cairo University.

3. Clinical and Chemical Pathology department, National Cancer institute, Cairo University, Egypt.

\begin{abstract}
Background: Colorectal cancer (CRC) has high morbidity and mortality rates. Invasive techniques and other laboratory tests with variable sensitivity and specificity are currently used in diagnosis. Micro ribonucleic acids (miRNAs) have bio vital roles in cell proliferation and apoptosis. Dys-regulation of miRNAs is linked to tumour genesis. The objective of this study was to evaluate the specificity and sensitivity of serum non-invasive biomarkers (micro-RNAs), miR-1246, miR-23a, and miR-451 in CRC patients.

Methods: Peripheral expression of three miRNAs (miR-1246, miR-23a and miR-451) was investigated in sera of 37 CRC Egyptian patients and 30 healthy controls, using quantitative real-time polymerase chain reaction trying to reach the optimal non-invasive combination of miRNAs.

Results: Serum miR-1246 was up-regulated in sera of CRC patients compared to normal controls (fold change $=3.55 ; \mathrm{P}<$ 0.001 ) and showed $100 \%$ sensitivity and $80 \%$ specificity in diagnosis of CRC. Serum miR-451 was significantly down-regulated in CRC patients (fold change $=-4.86 ; \mathrm{p}=0.014$ ), whereas, miR-23a was down-regulated but this was not statistically significant.

Conclusion: Up-regulation of miR-1246 and down-regulation of miR-451 in the sera of primary CRC Egyptian patients were confirmed with high sensitivity and specificity. Large-scale studies on a wider spectrum of miRNAs in Egyptian CRC patients are needed.

Keywords: miR-1246; miR-451; miR-23a.

DOI: https://dx.doi.org/10.4314/ahs.v20i3.33

Cite as: Salah M, Shaheen I, El-Shanawany P, Eid Saad N, Saad R, El Guibaly M, et al. Detection of miR-1246, miR23 a and miR451 in sera of colorectal carcinoma patients: a case-control study in Cairo University hospital. Afri Health Sci. 2020;20(3): 1283-1291. https:// dx.doi.org/10.4314/abs.v20i3.33
\end{abstract}

\section{Introduction}

Cancer, especially colorectal cancer (CRC), is considered as a major public health problem all over the world, with higher rates of both morbidity and mortality in low income countries that could be attributed to late presentation and the need of invasive diagnostic techniques in addition to the expensive long therapeutic modalities ${ }^{1-3}$.

\section{Corresponding author: \\ Iman A Shaheen, \\ Department of Clinical and Chemical Pathology, \\ Kasr Al-Ainy Faculty of Medicine, \\ Cairo University, Cairo, Egypt. \\ Email:iman.shym@yahoo.com}

Other laboratory tests with variable sensitivity and specificity including occult blood in stool, Carcino-embryonic Antigen (CEA) and Cancer Antigen (CA 19-9) are used in the diagnosis of $\mathrm{CRC}^{4-6}$.

Micro ribonucleic acids (miRNAs) are short single stranded non coding RNA with an average length of twenty nucleotides. They have been linked to cell proliferation, differentiation and apoptosis ${ }^{7}$.

Dys-regulation of miRNAs has been incriminated in the tumour genesis by unbalancing the equilibrium between oncogenic and tumour suppressor genes. ${ }^{8,9}$.

More than 100 miRNAs are dys-regulated in CRC. Several studies, the majority of which were conducted in the Far East, with a growing number of Egyptian ones ${ }^{10,11}$, have investigated different combinations of either circulating or extracted miRNAs from CRC tissues ;some of them showed contradictory results, even though they were conducted on the same ethnic group ${ }^{12,13}$. 
The miR-1246 is a transcriptional target of the tumour suppressor gene P53 and regulates its function. The studied function of miR-1246 in different human carcinomas alternated between either oncogenic or tumour suppression activities ${ }^{14}$. When miR-1246 was transferred to poorly metastasis oral cancer cells by exosomes it promoted its motility, moreover miR1246 levels were associated with advanced oesophageal carcinoma ${ }^{15}$.

MiR-23a is a part of intergenic miRNA cluster (miR23a/24-2/27a) located on chromosome $19 \mathrm{p} 13.12$ which is dys-regulated in breast cancer and other gastrointestinal associated malignancies such as hepatocellular carcinoma and pancreatic adenocarcinoma ${ }^{16}$.

MiR-451 is located on chromosome17q11.2 and it is up-regulated during foetal life to promote cell growth and differentiation, then it is down-regulated during adult life ${ }^{17}$. Its expression has significant differences in human malignancies including the gastrointestinal tract (GIT) (oesophageal, gastric and colorectal) ${ }^{18}$.

The current study aimed to investigate three miRNA (miR-1246, miR-23a and miR-451), other than those previously investigated in Egyptian studies trying to reach the optimal combination of miRNAs with the highest sensitivity and specificity in CRC diagnosis, which also could be used as molecular target therapy in the future aiming to decrease the morbidity and mortality rates of Egyptian CRC patients.

\section{Subjects and methods}

The current study included 37 CRC patients with a mean age of $49.1 \pm 16.42$ years. There were 15 males (40.5\%) and 22 females (59.5\%). Patients were selected from the National Cancer Institute, Cairo University, Egypt. Patients were recruited if they were above the age of 18 years, diagnosed with a new sporadic CRC, at any anatomical site and any stage of disease progression (based on the seventh edition of tumour-node-metastasis (TNM) staging system ${ }^{19}$. Patients were excluded from the study if they were diagnosed with familial adenomatous polyposis or hereditary non-polyposis colorectal carcinoma, had double malignancy, were subjected to definitive surgical management prior to blood sampling, or were subjected to chemotherapy or radiotherapy prior to blood sampling.

Sera from 30 age and sex matched individuals that underwent a complete physical screening at the Family Medicine outpatient clinic; Kasr-Alainy Hospital-Faculty of Medicine, Cairo University were used as healthy controls. The mean of their age was $49.43 \pm 13.63$ years; there were 18 males and 12 females.
Serum samples of all participants were stored at $-20^{\circ} \mathrm{C}$ until use. Patients and controls were subjected to routine laboratory workup including CEA and CA19-9 tumour markers.

This study was revised and ethically approved by the ethical committee of Clinical and chemical pathology and Family Medicine departments which were in accordance with the 2011 Declaration of Helsinki. All the participants provided informed consent.

The sample size was calculated via (Epicalc 2000) and based on study power of $95 \%$, p value 0.05 and matched cases control study 1 to 1 with odd ratio 3 .

\section{Purification of total RNA, including miRNA}

Serum contains primarily small RNAs, therefore enrichment of miRNAs is usually not required. Serum was mixed with500 $\mathrm{ml}$ of QIAzol Lysis Reagent (Qiagen) and the aqueous phase was collected by adding chloroform. After the addition of ethanol to the aqueous phase, total RNA including miRNA was purified using RNeasy MiniSpin Columns (Qiagen, Germany, Cat. No. 219610). miRNeasy Serum/Plasma Spike-In Control (Qiagen, Germany, Cat.No. 219610) which is a synthetic miRNA was used to spike the miRNA prep to monitor RNA recovery and reverse transcription efficiency. This synthetic miRNA was added to serum samples during the extraction procedure after the addition of denaturant (QIAzol Lysis Reagent), prior to addition of chloroform and phase separation.

\section{Quantitative Real Tome Polymerase chain reaction (qRT-PCR)}

The amounts of miRNAs in serum were quantified by qRT-PCR. The reverse transcription reaction was carried out in duplicate for each sample using miScript

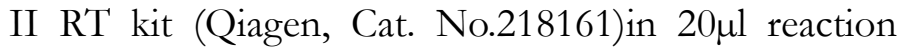
volume containing $1.5 \mu \mathrm{l}$ of purified RNA extract containing miRNeasy Serum/Plasma Spike-In Control, $4 \mu \mathrm{l}$ of5x miScript HiSpec Buffer, $2 \mu$ l of 10x miScript Nucleics Mix, $2 \mu$ l of miScript reverse transcription Mix and $10.5 \mu$ lof Nuclease-free water. For the synthesis of complimentary Deoxy Rribo-Nucleic Acid ( cDNA), reaction mixtures were incubated for $60 \mathrm{~min}$ at $37^{\circ} \mathrm{C}$ then incubated for $5 \mathrm{~min}$ at $95^{\circ} \mathrm{C}$ to inactivate miScript Reverse Transcriptase Mix before being placed on ice. Next the cDNA was diluted in RNase-free water; $200 \mu l$ of RNase-free water was added to the reverse transcription reaction. This results in a miRNeasy Serum/Plasma Spike-In Control concentration of $2.7 \times 10^{5}$ copies / $\mu$ l.The diluted reverse transcription reaction was used in real time PCR reaction with the desired primer assay. QRT-PCR was done using miScript syber green PCR kit 
(Qiagen, Cat. No.218073) and the 7500 Real-Time PCR System (Applied Biosystems), according to a standardized protocol. $2.5 \mu \mathrm{l}$ of diluted cDNA was added in a total of $25 \mu \mathrm{l}$ reaction volume containing $12.5 \mu \mathrm{l}$ of $2 \mathrm{x}$

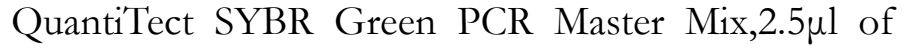
10xmiScript Universal Primer (reverse primer), $5 \mu$ of Nuclease-free water, $2.5 \mu \mathrm{l}$ of $10 \mathrm{x}$ miScript Primer Assay that is specific for the assayed target (MiR-1246 ( Qiagen Hs_miR-1246_2 miScript Primer Assay (MS00043491); MiR-23a; (Qiagen Hs_miR-23a_2 miScript Primer Assay (MS00031633) and MiR-451a; (Qiagen Hs_miR451_1 miScript Primer Assay (MS00004242): miR-39 was used as a house keeping gene. $\Delta \mathrm{Ct}$ as calculated as the studies miRNA expression minus the expression of the house keeping gene for each sample. The 2- $\Delta \Delta \mathrm{CT}$ method was used to calculate the fold change relative to the corresponding expression level of each miRNA in normal control.

\section{Statistical analysis}

The data were statistically described in the form of mean \pm standard deviation ( $\pm \mathrm{SD})$. When appropriate the median and range, or frequencies (number of cases) and percentages were used. Comparisons of numerical variables were done using the Mann Whitney $U$ test for independent samples when comparing twogroups. Kruskal Wallis test was used in comparing more than two groups. On comparing categorical data, the Chisquare (c2) test was performed. Correlations between various variables were done using Spearman rank correlation equation. Sensitivity and specificity were used to represent the accuracy. To determine the optimum cut off value for the studied diagnostic markers Receiver operator characteristic (ROC) analysis was used. P values less than 0.05 were considered statistically significant. All statistical calculations were done using the computer program SPSS (Statistical Package for the Social Science; SPSS Inc., Chicago, IL, USA).

\section{Results}

The present study is a case-control study which was conducted in the National Cancer Institute and the Family Medicine outpatient clinics, in Kasr-Alainy Faculty of Medicine, Cairo University. Thirty-seven CRC patients, fitting the inclusion criteria, were recruited from the National Cancer Institute. Fifteen (40.5\%) were males and $22(59.5 \%)$ were females, with a mean age of $49.43 \pm 13.63$ years; fourteen patients $(37.8 \%)$ were younger than 40 years old. Elevated serum level of CEA (more than $5 \mathrm{ng} / \mathrm{dl}$ ) was detected in 27 CRC patients $(73 \%)$ with a mean of $10.76 \pm 5.5 \mathrm{ng} / \mathrm{dl}$, while CA 19-9 was elevated (more than $37 \mathrm{U} / \mathrm{ml}$ ) in $23 \mathrm{CRC}$ patients $(62.2 \%)$ with a mean of $64.85 \pm 37.5 \mathrm{U} / \mathrm{ml}$ .Nine cases $(24.3 \%)$ were stage II, and 28 cases $(75.7 \%)$ had stage III colorectal carcinoma according to TNM staging system. The pathological examination revealed that all the examined tissues were adenocarcinoma $\mathrm{Ta}-$ ble (1). 
Table (1): Main clinical and laboratory findings of the CRC patients.

\begin{tabular}{|c|c|c|}
\hline \multicolumn{2}{|l|}{ Pathological features } & \multirow{2}{*}{$\begin{array}{l}\text { CRC cases } \\
\text { Total }(n=37) \% \\
19(51.4)\end{array}$} \\
\hline \multirow[t]{6}{*}{ Presenting symptoms } & Bleeding per rectum & \\
\hline & Tenesmus & $12(32.4)$ \\
\hline & Mucus per rectum & $17(45.9)$ \\
\hline & Chronic abdominal pain & $26(70.3)$ \\
\hline & Change in bowel habits & $23(62.2)$ \\
\hline & Unintentional weight loss & $23(62.2)$ \\
\hline \multirow[t]{4}{*}{ Site } & Rectal & $8(21.6)$ \\
\hline & Sigmoid & $6(16.3)$ \\
\hline & Left colon & $5(13.5)$ \\
\hline & Right colon & $18(48.6)$ \\
\hline Pathology & Adeno-carcinoma & $37(100)$ \\
\hline \multirow[t]{6}{*}{ TNM staging } & II A & $1(2.7)$ \\
\hline & II B & $6(16.2)$ \\
\hline & II C & $2(5.4)$ \\
\hline & III A & $5(13.5)$ \\
\hline & III B & $16(43.2)$ \\
\hline & III C & $7(18.9)$ \\
\hline \multicolumn{3}{|c|}{ Main laboratory findings (Mean \pm SD) } \\
\hline Haemoglobin (g/dl) & \multicolumn{2}{|l|}{$8.83 \pm 1.17$} \\
\hline CEA (ng/dl) & \multicolumn{2}{|l|}{$10.76 \pm 5.5$} \\
\hline CA $19-9(\mathrm{U} / \mathrm{ml})$ & \multicolumn{2}{|l|}{$64.85 \pm 37.5$} \\
\hline
\end{tabular}

As shown in table 2, the serum level of miR-1246 was normal control participants (fold change $=3.55 ; \mathrm{P}<$ significantly up-regulated in CRC patients compared to 0.001 )with a cut off value of $1.34 \Delta \mathrm{Ct}$ (Figure 1).

Table 2: The regulation pattern of miR-1246, miR-23a and miR-451in

CRC patients

\begin{tabular}{|l|l|l|l|l|l|l|l|}
\hline & Regulation & AUC & $\begin{array}{l}\text { Fold } \\
\text { change }\end{array}$ & $\boldsymbol{p}$ value & $\begin{array}{l}\text { Cut } \\
\text { off } \\
\text { value* }\end{array}$ & Sensitivity & Specificity \\
\hline $\begin{array}{l}\text { miR- } \\
1246\end{array}$ & Up & 0.924 & 3.55 & $<\mathbf{0 . 0 0 1}$ & 1.34 & 100 & 80 \\
\hline $\begin{array}{l}\text { miR- } \\
23 a\end{array}$ & Down & 0.67027 & -0.568 & 0.102 & N.S & N.S & N.S \\
\hline $\begin{array}{l}\text { miR- } \\
451\end{array}$ & Down & 0.757 & -4.86 & $\mathbf{0 . 0 1 4}$ & 0.685 & 73 & 80 \\
\hline
\end{tabular}

* $\Delta$ Ct: miRNA minus the house keeping gene

N.S: Non-significant

AUC: The Area Under the Curve 


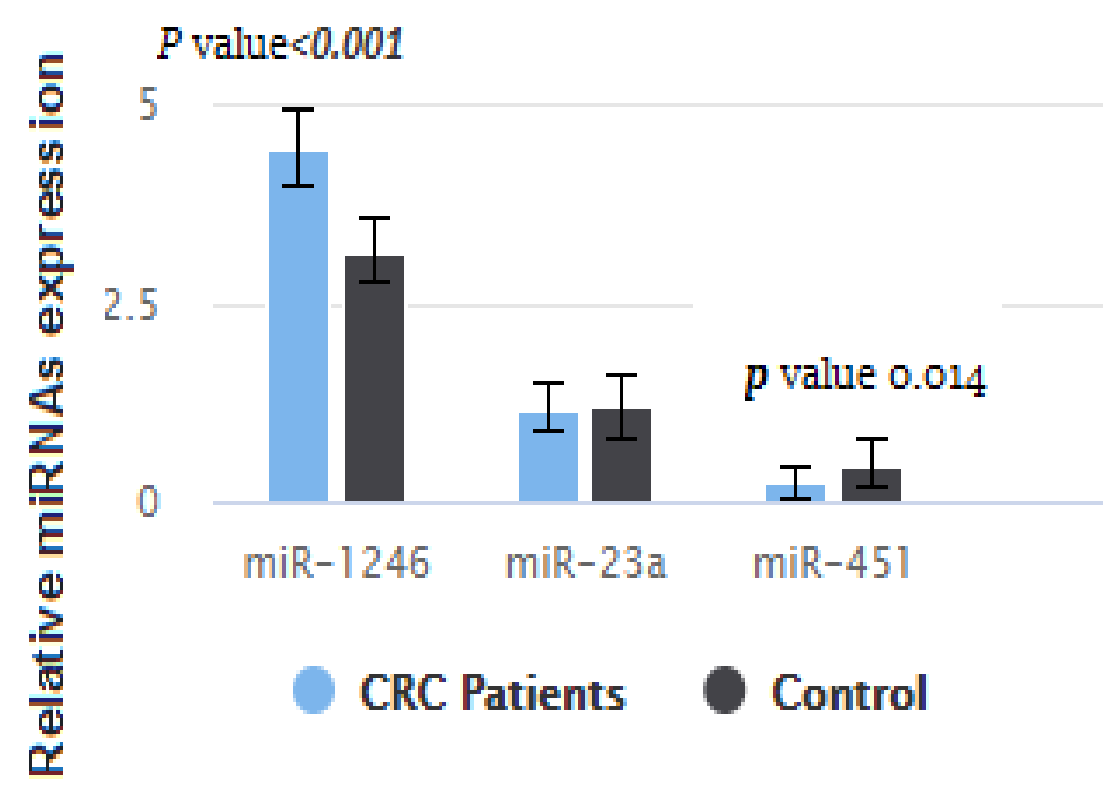

Figure (1): Relative expression of each target miR-1246, 23a and 451 normalized to reference gene (miR-39) in both patients and control groups

The ROC curve analysis showed that up-regulation of miR-1246 had 100\% sensitivity with $80 \%$ specificity inthe diagnosis of CRC (Figure 2).

Whereas miR-23a was down-regulated in the sera of
CRC patients compared to normal controls, this was not statistically significant (fold change $=-0.568 ; \mathrm{p}=$ 0.1015).By applying Spearman's Correlation a moderate inverse relation ( $r s=-0.449)$ between miRNA-23a and CEA $(p=0.005)$ was observed (Table 3$)$.

Table 3: Correlation between CEA and CA 19-9 serum levels and studies miRNAs expression in CRC patients

\begin{tabular}{|l|l|l|l|l|}
\hline \multicolumn{2}{|c|}{$\begin{array}{c}\text { CRC Patients } \\
(\mathbf{n}=\mathbf{3 7})\end{array}$} & miR-1246 & miR-23a & miR-451 \\
\hline \multirow{2}{*}{ CEA } & rs & -0.24 & -0.449 & -0.102 \\
\cline { 2 - 5 } & $\boldsymbol{p}$ value & 0.14 & $\mathbf{0 . 0 0 5}$ & 0.547 \\
\hline \multirow{2}{*}{ CA19-9 } & rs & -0.08 & 0.126 & -0.076 \\
\cline { 2 - 6 } & $\boldsymbol{p}$ value & 0.639 & 0.458 & 0.663 \\
\hline
\end{tabular}

Rs: Spearman's Correlation Coefficient

Serum levels of miRNA-451 was significantly down regulated in the sera of CRC patients compared to normal controls (fold change $=-4.86 ; p=0.014$ )with a cut off value of $0.685 \Delta \mathrm{Ct}$ (Figure 1). The ROC curve analysis showed that down-regulation of miR-451 had 73\% sensitivity with $80 \%$ specificity in diagnosis of CRC (Figure 2). 
(a)

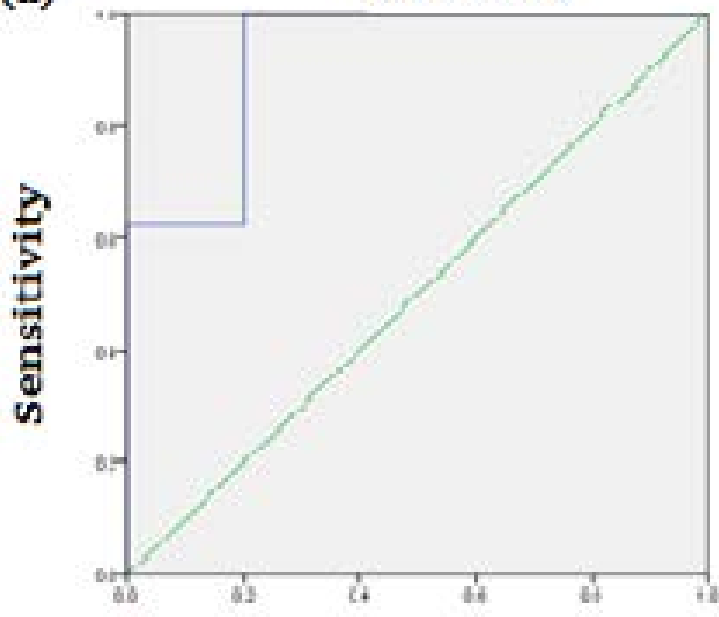

Sperificity b)

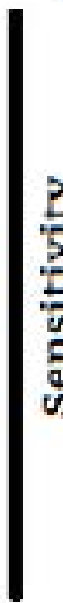

ROC curve

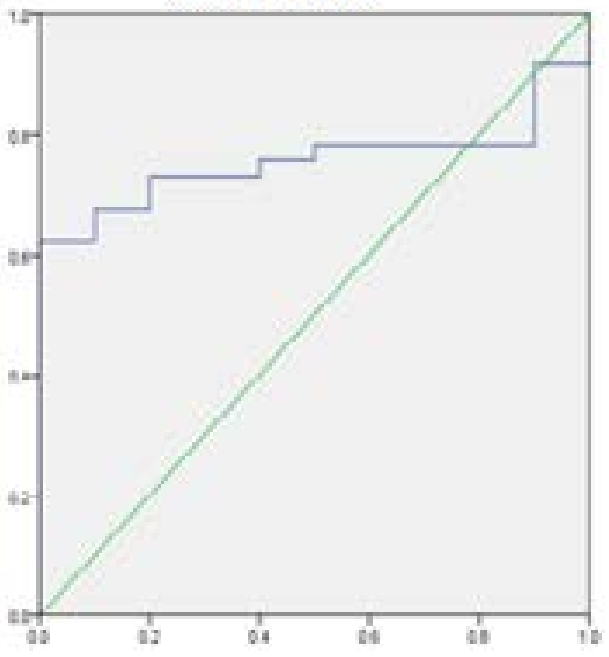

Specificity

Figure (2): ROC Curve of miR-1246 (a), ROC Curve of miR -451(b).

\section{Discussion}

A rapidly growing number of studies have been conducted to investigate the sensitivity and specificity of micro RNA, in different combinations, as diagnostic and / or prognostic markers in human malignancies ${ }^{20}$. More studies are still needed to investigate over $100 \mathrm{hu}-$ man miRNAespecially in late representing malignancies such as CRC ${ }^{21}$.

The objective of this study was to evaluate the specificity and sensitivity of serum non-invasive biomarkers (micro-RNAs), miR-1246, miR-23a, and miR-451in CRC patients.

The current study included 37 primary CRC Egyptian patients $59.5 \%$ of whom were females and more than one third $(37.8 \%)$ were below 40 years old.Similar findings were reported among CRC Egyptian patients ${ }^{2,22}$ and in CRC patients in the Gulf area and the Sudan ${ }^{23,24}$. These findings raise the need of future epidemiological studies in the Middle East, using more sensitive diagnostic tools, to evaluate the potentiality of CRC in young age groups and females.

None of the involved patients had early stage of CRC disease, as $24.3 \%$ had stage II and $75.7 \%$ had stage III. Similar findings were observed in other Egyptian ${ }^{25}$, Omani ${ }^{26}$ and African studies ${ }^{27}$. Most colon cancers are known to begin as adenomatous polyps, so by using colonoscopy to detect and excise the polyps can theoretically preventmost colon cancers. However, in practice, colonoscopy has failed to achieve this goal. Being expensive, invasive, and requiring prior bowel preparation in addition to the inconvenient procedure itself, pati- uents' compliance was found to be relatively low (40$50 \%$ in comparison to over $80 \%$ for breast, cervix and prostate cancers screening ${ }^{28}$. This increases the need for easy to perform, more sensitive and specific tests that can detect the early disease stages such as circulating miRNAs ${ }^{29}$. Serum miRNAs were noticed to be remarkably stable and their patterns of expression were found to be tissue-specific, making them good candidates for non-invasive cancer testing ${ }^{30}$.

Evidence supports the role of microRNAs in initiation stage of CRC, progression and development. Extensive research now aims at determining whether, in the near future, microRNAs can be used as diagnostic markers and at the same time therapeutic targets for cancer treatment. To date, many studies have examined microRNA patterns of expression in CRC and it was confirmed that the expression of microRNAs are altered in CRC in consistent and reproducible pattern ${ }^{12}$.

Contrary to the primary reports stating that miRNA expression levels are generally down-regulated in cancer, more miRNAs have been established to have up-regulated expression in CRC compared to those with reduced levels. Functional studies proved that some miRNAs have important oncogenic roles while others have bio-vital tumour suppressor functions which have to be properly assessed for each microRNA separately in the context of the specific tissue or tumour type?

The research team of this study aimed to identify and evaluate a panel of miRNAs that might be suitable for CRC detection. Micro-array analyses of miR1246, miR23a and miR-451 were performed by quantitative real 
time PCR. Serum levels of miRNA-1246 were up-regulated inprimary CRC patients compared to normal controls (fold change $=3.55 ; \mathrm{p}<0.000$ ) with $100 \%$ sensitivity and $80 \%$ specificity in detecting CRC. This was consistent with previous studies that indicated the up-regulation of miR-1246 levels in CRC sera, tissue and cell lines, ${ }^{74}$. Thus, miRNA-1246 appears to be a promising biomarker for non-invasive diagnosis of CRC.

MiR-1246 was investigated in hepatocellular carcinoma (HCC) and was found to have a discriminating power between metastasis and non-metastasis HCC among Egyptian patients ${ }^{31}$. Moreover it was a good molecular predictorforoverallsurvival and disease free survival rates of HCC patients even after liver transplantation ${ }^{32}$. miR-1246 is a p53 target: it regulates the expression of Down syndrome-associated kinase (DYRK1A), which inactivates a nuclear transcriptional factor called NFAT1C by phosphorylation and preventing it from nuclear localization ${ }^{33}$. Alteration of miR-1246 affected cell proliferation, colony formation ability and apoptosis. These functions are partially done through the direct targeting of nuclear factor I/B (NFIB) ${ }^{34}$.

In the present study, serum levels of miRNA-23a weredown-regulated inprimary CRC patients when compared to controls, but this finding was not statistically significant $($ fold change $=-0.568 ; \mathrm{p}=0.1015)$. There was a moderate inverse correlation between miRNA-23a and CEA ( $r s=-0.449 ; p=0.005)$, which could be considered as another clue of the down regulation of miRNA-23a inprimary CRC patients as it was inverselycorrelated with a tumour marker CEA.

Similar findings were observed in Malaysia by Yong et al. ${ }^{16}$ who demonstrated that miR-23a levels were significantly down-regulated in CRC sera in comparison to controls.

Expression of miR-23a was found to be decreased either in CRC cell lines ${ }^{15}$ or in excision tissues from $\mathrm{CRC}^{13}$.

On the other hand, Ogata Kawata et al. ${ }^{7}$ reported that miRNA-23a levels were significantly elevated in sera of Japanese CRC patients and were down-regulated after surgery, with no correlation between the levels of miRNA-23a in serum exosomes and serum levels of CEA and CA19-9.

Jahid et al. ${ }^{35}$ reported that miR-23a was up-regulated in American patients with stages I/II colorectal cancers, and that miR-23a probably promotes the migration and invasion of CRC cells. They also found that the inhibition of miR-23a in CRC cell lines resulted in a significant decrease in cell viability and thus promoted cancer cell apoptosis through activation of apoptosis protease activating factor (APAF) in CRC cell lines. Their study highlighted the potential application of miR-23a regulation axis in miRNA-based therapy and prognosis.

These inconsistencies may be explained by the differences in patient ethnicities, locations, genetic abnormalities, or CRC staging, or any combination of these factors. Differences in research techniques may also play a role in such inconsistencies.

In this study, serum levels of miRNA-451 were significantly reduced in primary CRC patients when compared with controls (fold change $=-4.86 ; \mathrm{p}=0.014$ ). Similarly, miR-451 was found to be down-regulated in CRC cells, where its expression caused a decrease in tumorigenesis and decreased resistance of colon cancer cells to chemotherapy. These data suggest that miR-451 is a novel candidate that could be used as a marker to predict response to chemotherapy in patients with CRC 17.

Furthermore, Bitarte and his colleagues ${ }^{18}$ obtained colonospheres from different colon carcinoma cells, and performed miRNA profiling. Results showed that miR451 was down-regulated in the colonspheres in comparison to the normal cells.

On the other hand, Link and colleagues ${ }^{20}$, sought to evaluate the feasibility of performing miRNA profiling in stool specimens and compare it to normal colonic mucosa tissues. Levels of faecal miR-451 were found to be appreciably higher in CRC patients compared to healthy controls. Faecal miR-451 level was increased significantly by the presence of blood.

Subsequent to the growing number of studies investigating the miRNAs in CRC, several meta analyses were conducted with results varying between the insignificant use of miRNA solely as a screening test for CRC $^{21}$. In 2017 still the controversy was there and this was attributed to the varied methods of handling and processing of microRNA which yieldincomparable or inconsistent results. Therefore it is necessary to establish standardized protocols for microRNA assesments to obtain consistent data and accurately quantifying microRNAs by using stable reference genes for each type of cancer $^{36}$. A recent meta-analysis in 2018 reported that the use of miRNAs as diagnostic and prognostic 
biomarkers, particularly in CRC, appeared to be an inevitable consequence of the advancement in genetics of oncology and gastroenterology $y^{37}$.

\section{Conclusion}

The up regulation of miR-1246, in addition to the down regulation of miR-451 in the sera of primary CRC Egyptian patients were confirmed with high sensitivity and specificity. These can be used as non invasive CRC molecular markers. Large-scale studies on a wider spectrum of miRNAs in Egyptian CRC patients are still needed to endorse the importance of using serum level of miRNAs as non-invasive, sensitive and specific testing in CRC.

\section{Conflict of interest}

None declared.

\section{References}

1. Siegel R, Ward E, Brawley O and Jemal A, (2011): Cancer statistics: The impact of eliminating socioeconomic and racial disparities on premature cancer deaths. CA Cancer J Clin 61:212.

2. Veruttipong D, Soliman S, Gilbert S, Blachlev T, Hablas A, Ramadan M, Rozek S and Seifeldin A, (2012): Age distribution, polyps and rectal cancer in the Egyptian population-based cancer registry. World Journal of Gastroenterology: Aug 14, 2012. 18(30):3997-4003.

3. Hanahan D and Weinberg R, (2011): Hallmarks of cancer: the next generation. Cell 2011; 144:646-74 PubMed .

4. Duffy M, Van Dalen A, Haglund C, Hansson L, Holinski-Feder E and Klapdor R, (2007): Tumor markers in colorectal cancer: European Group on Tumor Markers (EGTM) guidelines for clinical use. Eur J Cancer 2007; 43:1348-60 PubMed .

5. Boeck S, Stieber P, Holdenrieder S, Wilkowski R and Heinemann V, (2006): Prognostic and therapeutic significance of carbohydrate antigen 19-9 as tumor marker in patients with pancreatic cancer. Oncology. 2006; 70:255-264 PubMed .

6. Ballehaninna U and Chamberlain R, (2012): The clinical utility of serum CA 19-9 in the diagnosis, prognosis and management of pancreatic adenocarcinoma: an evidence based appraisal. J Gastrointest Oncol; 3:105-119. 7. Ogata-Kawata H, Izumiya M, Kurioka D, Honma Y, Yamada Y, Furuta K, Gunji T, Ohta H, Okamoto H and Sonoda H (2014): Circulating exosomal microRNAs as biomarkers of colon cancer. PLoS One, 9, e92921.

8. Wang Z, (2011): The Guideline of the Design and
Validation of MiRNA Mimics. Methods in Molecular Biology: Volume 676 of the series pp 211-223.

9. Lu J, Getz G, Miska E, Alvarez-Saavedra E, Lamb $\mathrm{J}$ and Peck D, (2005): MicroRNA expression profiles classify human cancers. Nature. 435 (7043):834-838.

10. Bahnassy AA, Salem SE, El-Sayed M, Khorshid O, Abdellateif MS, Youssef AS, Mohanad M, Hussein M, Zekri AN, Ali NM (2018) MiRNAs as molecular biomarkers in stage II Egyptian colorectal cancer patients. Exp Mol Pathol. ;105(3):260-271.

11. Zekri AR, Youssef AS, Lotfy MM, Gabr R, Ahmed OS, Nassar A, Hussein N, Omran D, Medhat E, Eid S, Hussein MM, Ismail MY, Alenzi FQ, Bahnassy AA. (2016);Circulating Serum miRNAs as Diagnostic Markers for Colorectal Cancer. PLoS One. 2016 May 2;11(5):e0154130.

12. Luo X, Stock C, Burwinkel B and Brenner H, (2013): Identification and evaluation of plasma microRNAs for early detection of colorectal cancer. PLoS One. 14; 8(5): e62880.

13. Xu X-H, Wu X-B, Wu S-B, Liu H-B, Chen R and Li Y, (2014): Identification of miRNAs Differentially Expressed in Clinical Stages of Human Colorectal Carcinoma-An Investigation in Guangzhou, China. Coleman WB, ed. PLoS One. 9(4): e 94060.

14. Yamada, N., Tsujimura, N., Kumazaki, M., Shinohara, H., Taniguchi, K., Nakagawa, Y., Naoe, T. and Akao, Y, (2014): Colorectal cancer cell-derived microvesicles containing microRNA-1246 promote angiogenesis by activating Smad 1/5/8 signaling elicited by PML down-regulation in endothelial cells. Biochim.Biophys. Acta, 1839, 1256-1272.

15. Xi Y, Shalgi R, Fodstad O, Pilpel Y, Ju J (2006): Differentially regulated micro-RNAs and actively translated messenger RNA transcripts by tumor suppressor p 53 in colon cancer. Clin Cancer Res 12: 2014-2024.

16. Yong L, Law W and Wang W, (2013): Potentiality of a triple microRNA classifier: miR-193a-3p, miR-23a and miR-338-5p for early detection of colorectal cancer. BMC Cancer. 13:280.

17. Bandres E, Bitarte N, Arias F, Agorreta J, Fortes P, and Agirre X, et al. (2009): microRNA-451 regulates macrophage migration inhibitory factor production and proliferation of gastrointestinal cancer cells. Clin Cancer Res; 15:2281-90.

18. Bitarte N, Bandres E, Boni V, Zarate R, Rodriguez J, Gonzalez-Huarriz M et al (2011): MicroRNA-451 is involved in the self-renewal, tumorigenicity, and chemoresistance of colorectal cancer stem cells. Stem Cells; 29(11):1661-71. 
19. Jun KH, Lee JS, Kim JH, Kim JJ, Chin HM, Park SM. (2014). The rationality of N3 classification in the $7^{\text {th }}$ edition of the International Union Against Cancer TNM staging system for gastric adenocarcinomas: a case-control study. Int J Surg. ;12(9):893-6.

20. Link A, Balaguer F, Shen Y, Nagasaka T, Lozano J, Boland R, and Goel A, (2010): Fecal microRNAs as novel biomarkers for colon cancer screening. Cancer Epidemiol Biomarkers Prev. Jul; 19(7): 1766-1774.

21. Zhou X, Dong Z, Yang Y, Du L, Zhang X and Wang C (2013): Limited diagnostic value of microRNAs for detecting colorectal cancer: a meta-analysis. Asian Pacific Journal of Cancer Prevention 2013; 14(8): 4699-4704.

22. Gado A, Ebeid B, Abdelmohsen A and Anthony A, (2014): Colorectal cancer in Egypt is commoner in young people: Is this cause for alarm? Alexandria Journal of Medicine.50(3);197-201.

23. Loney T, Aw TC, Handysides DG, Ali R, Blair I, Grivna M, Shah SM, Sheek-Hussein M, El-Sadig M, Sharif AA, El-Obaid Y.(2013) An analysis of the health status of the United Arab Emirates: the 'Big 4' public health issues. Glob Health Action. 5;6:20100.

24. Bishehsari F, Mahdavinia M, Vacca M, Malekzadeh R and Mariani-Costantini R, (2014): Epidemiological transition of colorectal cancer in developing countries: Environmental factors, molecular pathways, and opportunities for prevention. World J Gastroenterol. 20(20): 6055-6072.

25. Eisa H (2010): Colorectal Cancer in Upper Egypt, Does Age Make A Difference in Survival? Medical journal of Cairo University, volume 78, No. 2:145-150. 26. Kumar S, Burney I, Khawaja Farhan Zahid et al (2015): Colorectal Cancer Patient Characteristics, Treatment and Survival in Oman - a Single Center Study. Asian Pacific Journal of Cancer Prevention Article 9. Volume 16 (12): 4853-4858.

27. Chalya P L, Mchembe M D, Mabula J B et al (2013): Clinicopathological patterns and challenges of management of colorectal cancer in a resource-limited setting: a Tanzanian experience. World Journal of Surgical Oncology; 11: 88.
28. Sandouk F, Al Jerf F and Al-Halabi B (2013): Precancerous lesions in colorectal cancer. Gastroenterol Res Pract, 457901.

29. Ahmed F, Amed N, Vos P , Bonnerup C, Atkins J , Casey M, Nuovo G, Naziri W, Wiley J and Allison R, (2012): Diagnostic MicroRNA Markers to Screen for Sporadic Human Colon Cancer in Blood Cancer Genomics and Proteomics vol. 9 no. 4 179-192.

30. Qu K, Zhang K, Li H, Afdhal $\mathrm{N}$ and Albitar M (2011): Circulating microRNAs as biomarkers for hepatocellular carcinoma. J Clin Gastroenterol. 45:355-60.

31. Ahmed EK, Fahmy SA, Effat H, Wahab AHA (2019) Circulating MiR-210 and MiR1246 as Potential Biomarkers for Differentiating HepatocellularCarcinoma from Metastatic Tumors in the Liver. J Med Biochem. ;38(2):109-117.

32. Ng KT, Lo CM, Wong N, Li CX, Qi X, Liu XB, Geng W, Yeung OW, Ma YY, Chan SC, Man K (2016). Early-phase circulating miRNAs predict tumor recurrence and survival of hepatocellular carcinoma patients after liver transplantation. Oncotarget, 7:19824-39.

33. Zhang Y, Liao JM, Zeng SX and Lu H (2011). p53 downregulates Down syndrome-associated DYRK1A through miR-1246. EMBO Rep. 12:811-817.

34. Zhang Q, Cao LY, Cheng SJ, Zhang AM, Jin XS, Li $Y(2015) \cdot p 53-i n d u c e d$ microRNA-1246 inhibits the cell growth of human hepatocellular carcinoma cells by targeting NFIB. Oncol Rep.;33(3):1335-41.

35. Jahid S, Sun J, Edwards R, Dizon D, Panarelli N, Milsom J, Sikandar S, Gümüs Z and Lipkin S, (2012): miR-23a promotes the transition from indolent to invasive colorectal cancer. Cancer Discov. Jun; 2(6):540-53. 36. Lin J, Chuang CC, Zuo L. (2017) Potential roles of microRNAs and ROS in colorectal cancer: Diagnostic biomarkers and therapeutic targets Oncotarget, 8(10): 1732817346.

37. Hibner G, Kimsa-Furdzik M, Francuz T. (2018) Relevance of MicroRNAs as Potential Diagnostic and Prognostic Markers in Colorectal Cancer. Int J Mol Sci.;19(10). pii: E2944. 